\title{
Efetividade das vacinas anti-VHB (DNA-recombinante) em doadores de sangue de uma região endêmica para hepatite B no sul do Brasil
}

\author{
Effectiveness of recombinant DNA vaccines against hepatitis B in \\ blood donors in an endemic region of South Brazil
}

\author{
Andrea Petry ${ }^{1}$ e Emil J. Kupek ${ }^{2}$
}

\begin{abstract}
RESUM0
O objetivo deste estudo foi de estimar a efetividade das vacinas anti-VHB em um estudo longitudinal, retrospectivo composto por 1.012 doadores de sangue que completaram o esquema padrão de vacinação ( três doses, incluindo doses de reforço nos doadores com títulos de anti-HBs <10UI/L) durante o período entre 1998 e 2002. Os resultados mostram que a taxa de soroconversão foi significativamente menor nos doadores cujo título de anti-HBs foi mensurado após seis meses decorridos do término do esquema de vacinação e nos doadores com mais de 50 anos. A efetividade média correspondeu a 88,7\%, variando de 80,6\% nos com maior idade (50 anos ou mais) a 91,4\% nos doadores mais jovens ( 18 a 30 anos). 0 regime de dose de reforço foi efetivo, principalmente por reduzir o percentual de não-respondedores. Conclui-se que a efetividade da vacina foi significativamente maior nos doadores mais jovens e que o tempo decorrido entre a vacinação e a testagem interferiu na taxa de soroconversão.
\end{abstract}

Palavras-chaves: Hepatite B. Vacina. Anti-HBs. Efetividade. Doadores de sangue.

\begin{abstract} influenced the vaccine effectiveness.

Key-words: Hepatitis B. Vaccine. Anti-HBs. Effectiveness. Blood donors.

A hepatite B é uma doença infecciosa, imunoprevinível, causada pelo vírus da hepatite B (VHB). Apresenta distribuição mundial, sendo considerada um alarmante problema de saúde pública. São estimados anualmente um milhão de óbitos no mundo devido à cirrose hepática ou ao carcinoma hepatocelular decorrentes da hepatite B. Dentre os agentes oncogênicos conhecidos para o desenvolvimento de câncer em humanos, 0 vírus VHB ocupa 0 segundo lugar, depois do tabaco ${ }^{19}$.
\end{abstract}

The objective of this work was to estimate the effectiveness of $D N A$ recombinant anti- $H B V$ vaccines in a retrospective cohort study of 1,012 Brazilian blood donors who completed the vaccination schedule ( 3 doses + booster of antibody titer $<10 I U / L$ ) during the period 1998-2002. The results showed that seroconversion rates were significantly lower among the donors whose antibody titers was measured six months after completing the vaccination scheme and among older donors, particularly those aged over 50. Overall vaccine effectiveness was $88.7 \%$, ranging from $80.6 \%$ in the oldest ( 50 years or over) to $91.4 \%$ among the youngest (18-30 years) donors. The booster regimen was effective at reducing the percentage of non-responders. We conclude that vaccine effectiveness was significantly better in younger blood donors and that the anti-HBs testing interval

0 Estado de Santa Catarina apresenta a maior taxa de detecção para a hepatite B, com 117 casos por 100.000 habitantes anualmente. A região do oeste do estado catarinense constitui-se em uma área com alta prevalência, com 7\% dos indivíduos sendo caracterizados portadores crônicos do vírus $\mathrm{B}^{6}$.

Essa situação tem demandado grandes esforços das unidades hemoterápicas em reduzir o risco de contaminação do VHB através dos hemocomponentes transfundidos. Como

\footnotetext{
1. Centro de Hematologia e Hemoterapia de Santa Catarina, Florianópolis, SC, Brasil. 2. Departamento de Saúde Pública da Universidade Federal de Santa Catarina, Florianópolis, SC, Brasil.

Endereço para correspondência: Dra. Andrea Petry. Laboratório de Sorologia/HEMOSC. Av. Prof. Othon Gama D’Eça 756, Centro, 88015-240 Florianópolis, SC. Tel: 5548 3251-9719; Fax: 5548 3251-9721

e-mail: deapetry@yahoo.com.br

Recebido para publicação em 15/7/2005

Aceito em 8/9/2006
} 
resultado dessas ações, a prevalência do HBsAg entre os doadores de sangue no estado, reduziu de 0,98\% para 0,6\% entre os anos 1999 e $2001^{15}$. Durante esse mesmo período, a prevalência do anti- $\mathrm{HBc}$ também reduziu de 8,8\% para 5,3\%. Contudo, apesar dos grandes avanços promovidos na seleção dos doadores e na testagem sorológica, 0 risco residual da transmissão do VHB através de transfusões sangǘneas na capital catarinense foi superior a 1:2.077 doações no final da década de 1990, devido principalmente a elevada incidência do vírus VHB de $3(1,35-5,77)$ por 1.000 pessoas-ano em doadores de sangue de repetiçãa $0^{10}$.

A melhor forma de prevenção contra a infecção pelo VHB é a vacinação ${ }^{18}$. Sua eficácia já foi demonstrada em recém-nascidos (99\%), adolescentes ( $95 \%$ ou mais), imunossuprimidos ou pacientes hemodialisados (50-70\%) e pacientes com doenças hepáticas (60-70\%), dentre outros ${ }^{19}$. 0 objetivo deste estudo foi de estimar a efetividade das vacinas anti-VHB (DNArecombinante) administradas aos doadores de sangue na região meio-oeste do estado de Santa Catarina que se constitui em uma área endêmica com alta prevalência do VHB. A medida da taxa de efetividade foi escolhida e não a de eficácia devido às dificuldades em conduzir um estudo controlado em uma unidade hemoterápica, 0 que poderia interferir nas atividades diárias. A efetividade também foi utilizada por se tratar de uma medida mais realista do efeito da vacina em um serviço de saúde no qual não ocorrem as condições ideais de um ensaio clínico.

\section{MATERIAL E MÉTODOS}

A população do estudo correspondeu a 19.114 doadores de sangue. Todos pertenciam à faixa etária entre 18 a 60 anos e compareceram no período de 20 de julho de 1998 a 31 de dezembro de 2002, no Hemocentro Regional de Joaçaba para realizar doações de sangue. № período foram realizadas 24.692 doações de sangue. Do total, 8.224 foram doadores de repetição.

0 período do estudo marca 0 início da vacinação dos doadores de sangue aptos pela rede pública através das vacinas fornecidas pelo Ministério da Saúde, através do Programa Nacional de Imunizações (PNI). As vacinas administradas no período foram Engerix- $B^{\circledast}$ (SmithKline Beecham Biologicals), Euvax- $\mathrm{B}^{\circledR}$ (LG Chemical, Korea), e ButaNG ${ }^{\circledR}$ (Instituto Butantã, São Paulo, Brasil).

Os indivíduos incluídos no estudo foram os doadores de sangue de repetição $(n=8.224)$. Estes apresentaram todos os marcadores sorológicos recomendados para a triagem de doadores de sangue, comprovadamente não reagentes (sífilis, hepatites B e C, anti-HIV e anti-HTLV, doença de Chagas). Os doadores participantes no estudo apresentaram, no mínimo, uma doação prévia antes da vacinação anti-VHB, sendo que nenhum foi vacinado previamente.

Foram excluídos doadores que não receberam a vacina anti-VHB, que não apresentaram documento de comprovação de vacinação e/ou com marcadores sorológicos reagentes para as doenças testadas no Hemocentro, e também aqueles cujo intervalo entre a realização do teste e aplicação da terceira dose a vacina foi inferior a 60 dias.

Os doadores foram considerados aptos após uma entrevista onde eram indagados sobre comportamentos de risco acrescido e doenças pré-existentes. Foram verificados indicadores gerais de saúde (temperatura axilar, peso, altura, pressão arterial e pulso, além do hematócrito), os quais estavam adequados. As amostras coletadas foram submetidas a testes sorológicos para detecção de anticorpos anti-HIV-1 e 2, antígeno de superfície do vírus da hepatite B (HBsAg), anticorpos totais anticore do VHB (anti-HBc), anticorpos contra 0 vírus da hepatite $\mathrm{C}$ (anti-VHC), anticorpos contra 0 vírus linfotrópico das células T humanas, tipos I/II, anticorpos anticardiolipina para a detecção de portadores de sífilis, utilizando a técnica Veneral Disease Research Laboratory, anticorpos anti-Trypanosoma cruzi. Na detecção dos marcadores sorológicos para a hepatite B, foram utilizados kits diagnósticos das empresas Chiron e Organon Teknica/Biomerieux.

As vantagens da imunização contra 0 VHB e 0 esquema de vacinação foram informadas aos 1.139 doadores aptos de repetição que participaram do estudo. Houve 0 consentimento verbal dos participantes, 0 qual foi registrado na ficha de cadastro dos doadores.

0 esquema de vacinação compreendeu três doses de $20 \mathrm{mcg} / \mathrm{mL}$ aplicados via intramuscular no deltóide. A segunda e a terceira dose foram administradas um e seis meses respectivamente, após a dose inicial. Os doadores que completaram 0 esquema vacinal foram testados para 0 anticorpo anti-HBs utilizando imunoensaio semiquantitativo na doação seguinte. Os doadores que apresentaram títulos de anti-HBs inferiores a 10UI/L foram considerados não-respondedores ${ }^{2}$ e foram submetidos à dose( $\mathrm{s}$ ) de reforço de $20 \mathrm{mcg} / \mathrm{mL}$. 0 mesmo procedimento foi repetido até três vezes em cada doação subseqüente para obter 0 título mínimo de 10UI/L de anti-HBs nos doadores. Um pouco menos da metade $(47,7 \%)$ dos doadores foram testados para anti-HBs dentro de seis meses após terem completado o esquema vacinal de três doses, 26,8\% entre seis e doze meses e o restante após um ano do término do esquema vacinal. Os técnicos que realizaram os testes laboratoriais desconheciam as amostras que pertenciam aos doadores vacinados.

A análise estatística foi focalizada na relação entre os níveis de produção de anti-HBs (não-respondedores com <10UI/L, fracos-respondedores com 10-99U//L e bons-respondedores com 100UI/L ou mais) e idade, gênero, cor da pele, intervalo entre a realização do testes e 0 término do esquema vacinal e 0 regime de dose de reforço. 0 teste de qui-quadrado de Pearson foi utilizado como teste de associação na análise univariada para testar 0 efeito das variáveis e 0 desfecho ( alcançar 0 título mínimo de 10U/L de anti-HBs ou não) . A técnica estatística regressão logística multivariada analisou o mesmo desfecho em relação às variáveis: tempo decorrido após a última dose da vacina, faixa etária, gênero, cor da pele e dose de reforço.

Cento e vinte e sete doadores foram excluídos por não apresentarem dados completos sobre 0 esquema de vacinação ou porque os níveis de anti-HBs foram medidos em um 
intervalo inferior a 30 dias após o término do esquema vacinal. Desta forma 0 tamanho da amostra foi reduzido para 1.012 indivíduos.

\section{RESULTAD0S}

A maioria (96,7\%) dos 1.012 doadores de sangue incluídos na análise apresentava cor da pele branca. A faixa etária predominante era dos 18 a 30 anos (40,2\%), seguida pelos indivíduos entre 31 e 40 anos (32,8\%). Um pouco mais da metade dos doadores pertenciam ao gênero masculino (53,6\%). Todos os doadores pertenciam à macro-região de Joaçaba que apresenta uma população estimada em 576.000 habitantes, em 2003.

Amédia da efetividade das vacinas recombinantes, utilizando como valor de corte 10UI/L, foi de $88,7 \%$, variando de $80,6 \%$ nos doadores com maior idade ( 50 anos ou mais) a $91,4 \%$ nos mais jovens (18-30 anos) (Tabela 1). Quando 0 valor de corte de 100UI/L foi utilizado, a efetividade média foi reduzida para $69,3 \%$, variando de $61,3 \%$ nos doadores com maior idade a $75,4 \%$ no grupo mais jovem. A queda da taxa de soroconversão relacionada com a faixa etária foi estatisticamente significativa (Tabela 1). Ambos os níveis de produção de anticorpos de 10-9UI/L e < 10UI/L seguem o mesmo comportamento de queda, embora note-se que esta foi acelerada após os 50 anos de idade, principalmente devido ao aumento dos nãorespondedores.

Tabela 1 - Análise univariada dos niveis de produção do anti-HBs (\%).

\begin{tabular}{|c|c|c|c|c|c|c|c|}
\hline \multirow[b]{2}{*}{ Variáveis } & \multirow[b]{2}{*}{ Categorias } & \multirow[b]{2}{*}{$\mathrm{N}$} & \multicolumn{3}{|c|}{$\begin{array}{c}\text { Nível de produção } \\
\text { do anti-HBs (\%) }\end{array}$} & \multirow{2}{*}{$\begin{array}{c}\text { Qui- } \\
\text { quadrado }\end{array}$} & \multirow[b]{2}{*}{$\mathrm{p}$} \\
\hline & & & $\begin{array}{l}<10 \\
\mathrm{UI} / \mathrm{L}\end{array}$ & $\begin{array}{r}10-99 \\
\text { UI/L }\end{array}$ & $\begin{array}{r}\leq 100 \\
\mathrm{UU} / \mathrm{L}\end{array}$ & & \\
\hline Tempo decorrido & $2-6$ & 483 & 0,4 & 19,5 & 80,1 & 118,286 & 0,001 \\
\hline após a última & $7-12$ & 271 & 22,9 & 17,3 & 59,8 & & \\
\hline dose da vacina & $13-24$ & 181 & 17,1 & 21,5 & 61,3 & & \\
\hline (meses) & $\geq 25$ & 77 & 24,7 & 22,1 & 53,2 & & \\
\hline Faixa etária & $18-30$ & 407 & 8,6 & 15,9 & 75,4 & 17,059 & 0,009 \\
\hline \multirow[t]{3}{*}{ (anos) } & $31-40$ & 332 & 11,4 & 20,8 & 67,8 & & \\
\hline & $41-50$ & 211 & 13,7 & 24,2 & 62,1 & & \\
\hline & $>50$ & 62 & 19,3 & 19,3 & 61,3 & & \\
\hline \multirow[t]{2}{*}{ Gênero } & masculino & 542 & 12,4 & 18,3 & 69,4 & 2,112 & 0,348 \\
\hline & feminino & 470 & 10,0 & 20,8 & 69,1 & & \\
\hline \multirow[t]{3}{*}{ Cor da pele } & branca & 979 & 11,3 & 19,7 & 68,9 & 2,910 & 0,573 \\
\hline & negra & 4 & 25,0 & 0,0 & 75,0 & & \\
\hline & outra & 29 & 6,9 & 13,8 & 79,3 & & \\
\hline \multirow[t]{2}{*}{ Dose de reforço } & não & 961 & 11,2 & 18,5 & 70,2 & 11,335 & 0,003 \\
\hline & sim & 51 & 11,7 & 37,2 & 51,0 & & \\
\hline
\end{tabular}

0 maior intervalo de tempo entre a última dose da vacina e a realização do teste anti-HBs ocasionou significativo impacto nos índices de soroproteção entre as variáveis analisadas. Cerca de $95 \%$ dos doadores que tiveram os títulos de anti-HBs medidos no período entre 2-6 meses alcançaram níveis de 10UI/L, comparados com 77,1\% para 7-12 meses, $82,8 \%$ para $13-24$ meses e $75,3 \%$ para o intervalo de 25 ou mais meses (Tabela 1). Ordem similar das diferenças foi observada quando utilizado 0 valor de corte de 100UI/L.

Dos 51 vacinados com dose de reforço, 43 receberam uma dose, sete receberam duas doses e um recebeu três doses de reforço. 0 reforço foi efetivo reduzindo o percentual de doadores não-respondedores (Tabela 1). Nenhuma evidência estatisticamente significativa foi encontrada na soroconversão devido a gênero ou cor da pele. Verifica-se que existe na população do estudo um pequeno número de indivíduos nãobrancos, o que impede conclusões objetivas sobre esta variável.

A regressão logística multivariada ( Tabela 2) confirma os efeitos acentuados do intervalo de tempo decorrido entre a última dose e a realização do teste anti-HBs. Por exemplo, os doadores testados no intervalo entre 7 a 12 meses apresentaram uma chance de $98,6 \%$ (i.e. a diferença percentual entre 0,014 e a linha de base) em obter títulos de 10U//L ou mais quando comparados aqueles cujo título foi mensurado em intervalo inferior a seis meses decorridos da última dose da vacina. Similar ordem de redução na chance de alcançar esse nível de proteção foi observada para os doadores com intervalos mais longos entre a última dose da vacina e a medida do título. Outro efeito estatisticamente significativo na análise multivariada foi relacionado à faixa etária dos doadores. Observa-se a redução na chance de produção de níveis de anti-HBs acima de 10UI/L na ordem de $2,2 \%$ ao ano.

Tabela 2 - Regressão logística multivariada para o título de anti-HBs de 10U/L

\begin{tabular}{lll}
\hline Variáveis & Categoria & OR (IC 95\%) \\
\hline Tempo decorrido após a & $>25$ & $0,013(0,003-0,055)$ \\
última dose da vacina & $13-24$ & $0,021(0,005-0,088)$ \\
(meses) & $7-12$ & $0,014(0,003-0,059)$ \\
& $2-6$ & $1,000 *$ \\
Idade (anos) & a cada ano & $0,978(0,959-0,998)$ \\
\hline
\end{tabular}

* linha de base.

odds ratio (OR) e correspondente intervalo de confiança de 95\% (IC) para as variáveis com efeitos estatisticamente significativos $(\mathrm{p}<0,05)$.

\section{DISCUSSÃ0}

A efetividade das vacinas anti-VHB (DNA recombinante) no grupo de doadores de sangue foi baixa quando comparada à maioria dos estudos com adultos saudáveis ${ }^{34} 19$, incluindo estudos com a vacina brasileira ButaNG, Engerix-B ${ }^{8}$ e Euvax$\mathrm{B}^{11}{ }^{17}$. Esse fato é surpreendente porque os doadores aptos de repetição são considerados menos expostos a fatores de risco acrescido para diversas doenças capazes de reduzir a imunogenicidade da vacina, comparados com a média da população, devido aos procedimentos de triagem realizados antes da doação de sangue. Por outro lado, mais de um quarto dos doadores teve a concentração de anti-HBs mensurada no intervalo superior a um ano após a terceira dose do esquema padrão de vacinação, e outro um quarto após treze meses. Grande declínio no título dos anticorpos foi observado nesse interval $0^{1416}$, quando comparados com os obtidos entre seis e doze meses. 
Um estudo multicêntrico realizado em clínica para viajantes mostra efetividade similar $(88,6 \%)$ deste tipo de vacina em adultos saudáveis, seis meses após terem completado a terceira dose do esquema de vacinação ${ }^{14}$. Contudo a efetividade nos 483 doadores de sangue testados nesse mesmo intervalo mostra uma efetividade de 99,6\% - um percentual surpreendentemente alto. A efetividade média dos doadores de sangue foi reduzida devido à maioria ter sido submetida ao teste no intervalo superior a seis meses, no qual 0 título de anti- $\mathrm{HBs}$ foi aproximadamente $20 \%$ mais baixo. Assim a efetividade média combina um índice extremamente baixo e outro elevado no cálculo de soroproteção em um único percentual.

A abrangente revisão de 181 estudos clínicos, publicada por Coates cols ${ }^{3}$ mostra que $92,2-94,5 \%$ dos adultos saudáveis ( trabalhadores da área da saúde), quando vacinados com 0 esquema de três doses, apresentam títulos de anti-HBs iguais ou superiores a 10UI/L. Essa comparação mostra que a taxa de soroproteção encontrada nos doadores de sangue estudados ( 88,7\%) é inferior, porém essa média encontrada nos doadores deve ser interpretada com cautela.

A relação inversa entre os níveis de produção de anticorpo e a idade dos vacinados foi demonstrada em uma meta-análise ${ }^{5}$ a qual também revelou que somente após os 30 anos de idade essa diferença na imunogenicidade pode ser notada. Este achado pode ser confirmado nos doadores de sangue vacinados. É importante ressaltar que 0 percentual de não-respondedores aumenta consideravelmente após os 50 anos de idade. Outros dois estudos brasileiros mostram 0 efeito da idade em profissionais da área da saúde, indicando que a resposta imune à vacina é significativamente inferior em indivíduos com mais de $35 \mathrm{anos}^{4}{ }^{8}$. Um estudo realizado em Portugal com trabalhadores da área da saúde também demonstrou melhor imunogenicidade em indivíduos mais jovens ${ }^{12}$.

Embora alguns estudos demonstrem não haver significantes diferenças na imunogenicidade frente à vacina em relação ao gêner $0^{91317}$, outros autores encontraram maior taxa de não-respondedores em mulheres ${ }^{12}{ }^{14}$ sendo que outros encontraram maior taxa de respondedores em mulheres adolescentes ${ }^{71}$. Em relação à efetividade da dose de reforço, no entanto, há uma razoável concordância na redução do percentual de fracos-respondedores e aumento na concentração de anti-HBs, como mostram os estudos de Ayerbe cols ${ }^{1}$ e Perera cols ${ }^{13}$, dentre outros.

Os resultados dessa primeira avaliação da efetividade da vacina anti-VHB devem ser vistos com cautela devido às limitações do estudo, dentre elas a falta de informação sobre exatamente qual vacina DNA recombinante foi aplicada a nível individual. Embora essa informação seja facilmente obtida, simplesmente não era anotada nos comprovantes de vacinação dos doadores. Como a efetividade obtida no estudo foi semelhante à eficácia obtida na revisão realizada por Coates $\mathrm{cols}^{2}$, esse fato faz-nos acreditar que essa informação não alteraria os resultados do estudo realizado com os doadores de sangue. Por exemplo, Fisman cols $s^{5}$ mostraram que as vacinas Engerix B e Recombivax eram significativamente menos eficientes em indivíduos com maior idade. A determinação do título médio geométrico também foi outra informação relevante não disponível neste estudo, porque todos os valores acima de 100UI/L não foram mensurados a nível quantitativo. Outras limitações incluem a falta de um grupo controle para verificar a incidência da hepatite B em grupos de indivíduos vacinados e não vacinados.

Embora 0 Brasil tenha adotado a vacinação universal de crianças e adolescentes contra a hepatite B, sua implantação é muito recente e sua cobertura é muito baixa no contexto da doação de sangue. Portanto, oferecer vacinas anti-VHB efetivas a população de doadores de sangue constitui-se em um instrumento para a redução da incidência de hepatite B nesta população e em contrapartida tornará 0 sangue doado mais seguro por evitar a contaminação pelo VHB.

\section{AGRADECIMENTOS}

Os autores agradecem ao Dr. Nilson F. Dorl e as enfermeiras Ana Maria Maresch, Christina M. Massignan, Regina S. Fontana e Solange Bertoldi, e aos doadores de sangue do HEMOSC-Joaçaba, que participaram no estudo.

\section{REFERÊNCIAS BIBLIOGRÁFICAS}

1. Ayerbe MC, Perez-Rivilla A, ICOVAHB group. Assessment of long-term efficacy of hepatitis B vaccine. European Journal of Epidemiology 17:150156, 2001.

2. Centers for Diseases Control and Prevention, Immunization Practices Advisory Committee. Recommendations of the Update on Hepatitis B Prevention. Morbidity and Mortality Weekly Report MMWR 36:353-353, 1987.

3. Coates T, Wilson R, Patrick G, Andre F, Watson V. Hepatitis B vaccines, assessment of the seroprotective efficacy of two recombinant DNA vaccines. Clinical Therapy 23:392-403, 2001.

4. Ferraz MLG, Silva AEB, Kemp VL, Cruz CN, Guimarães R. Avaliação da resposta imunológica à vacina contra a hepatite $\mathrm{B}$ em profissionais da área da saúde. Revista da Associação Médica Brasileira 38:5-8, 1992.

5. Fisman D, Argrawal D, Líder K. The effect of age on immunologic response to recombinant hepatitis $B$ vaccine. A meta-analysis. Clinical Infection Diseases 35:1368-75, 2002.

6. Fundação Nacional de Saúde. Hepatite B. In: Situação do Controle e da Prevenção das Doenças Transmissíveis no Brasil. Ministério da Saúde, p.33-35, 2002.

7. Heron LG, Chant KG, Jalaludin BB. A novel hepatitis B vaccination regimen for adolescents: two doses 12 months apart. Vaccine 4:3472-3476, 2002.

8. Ioshimoto LM, Rissato ML, Bonilha VSJ, Miyaki C, Raw I, Granovski, N. Safety and immunogenicity of hepatitis B vaccine ButaNG in adults. Revista do Instituto de Medicina Tropical de São Paulo 41:191-193, 1999.

9. Keating GM, Noble S. Recombinant hepatitis B vaccine (Engerix - $B^{\circledR}$ ): A Review of its Immunogenicity and Protective Efficacy Against Hepatitis B.[Miscellaneous Article]. Drugs 63: 1021-1051, 2003.

10. Kupek E. Residual transfusion risk for hepatitis B and Cin southern Brazil, 1991-99. Journal of Viral Hepatitis 8:78-82, 2001.

11. Lopes CLR, Martins RMB, Teles SA, Silva SA, Maggi PS, Yoshida CFT. Perfil soroepidemiológico da infecção pelo vírus da hepatite B em profissionais das unidades de hemodiálise de Goiânia-Goiás, Brasil Central. Revista da Sociedade Brasileira de Medicina Tropical 34: 543-548, 2001.

12. Marinho RT, Pedro M, Ramalho F, Velosa J, De Moura MC. Vacinação contra hepatite B: oito anos de experiência. Acta Medica Portuguesa 11: 971977, 1998. 
13. Perera J, Perera B, Gamage S. Seroconversion after hepatitis B vaccination in healthy young adults, and the effect of a booster dose. Ceylon Medical Journal 47: 6-8, 2002.

14. Rendi-Wagner P, Kundi M, Stemberger H, Wiedermann G, Holzmann Hofer $\mathrm{M}$, Wiesinger $\mathrm{K}$, Kollaritsch $\mathrm{H}$. Antibody-response to three recombinant hepatitis $B$ vaccines, comparative evaluation of multicenter travel clinic based experience. Vaccine 19:2055-2060, 2001.

15. Rosini N, Mousse D, Spada C, Treitinger A. Seroprevalence of HBsAg, AntiHBC and anti-HCV in Southern Brazil, 1999-2001. Brazilian Journal of Infectious Diseases 7:262-267, 2003.
16. Scheiermann N, Gessemann M, Maurer C , Just M, Berger R. Persistence of antibodies after immunisation with a recombinant yeast-derived hepatitis B vaccine following two different schedules. Vaccine 8: 844-846, 1990.

17. Teles SA, Martins RMB, Lopes CLR, Carneiro MAS, Souza KP, Yoshida CFT. Immunogenicity of a recombinant hepatitis B vaccine (Euvax-B) in hemodialysis patients and staff. European Journal of Epidemiology 17:145-149, 2001.

18. World Health Organization. Hepatitis B vaccine, making global progress. EPI, Geneve, 1996.

19. World Health Organization. Hepatitis B. Disponível em: <www.who.int/ inf.fs/en/fact2004.html> Acesso em 5 junho de 2003. 